\title{
Peer Assessment for Construction Management and Quantity Surveying Students
}

Patricia McLaughlin and Nicholas Simpson (Department of Property, Construction and Project Management, RMIT University, Australia)

\section{ABSTRACT}

Students undertaking the Bachelor of Construction Management degree course at RMIT University, Melbourne, qualify for registration with the Australian Institute of Quantity Surveyors (AIQS) and the Australian Institute of Building (AIB) upon graduation. Over the past decade the degree course has been constantly upgraded and altered in line with recommendations from professional bodies such as these and other industry partners. In 1994 the Department of Building and Construction Economics re-assessed a range of subjects including the first year technology subjects. Out of the review a problem-based integrated learning unit was developed and tested. This unit has now been in place for ten years.

Quantity surveying and construction management like most other professions in the construction industry require teamwork and advanced consultation skills. These skills may be learnt through experience but there is considerable evidence that these skills can be taught in the undergraduate years. Therefore in line with team-based approaches used in industry and professional construction settings, this year a new assessment model - peer assessment - will be applied to the problem-based learning unit. This paper describes the procedures and processes used to introduce the change and examines the theoretical base upon which the model was developed.

Keywords: Teamwork, peer assessment, industry based learning, group assessment and construction.

\section{INTRODUCTION}

'Team interaction and assessment is a basic requirement in a changing environment such as building. It is fundamental to a healthy industry' (McGettigan, 1985: 186).

The construction industry is characterised by the interaction of a range of professionals, tradespeople and other workers. Construction management undergraduate degrees emphasise the importance of an integrated team approach. Curriculum is arranged into units that reflect the construction environment based upon industry input and professional recognition. Each profession in the construction industry relies upon a teamwork system to complete projects to the required standard. McGettigan (1985) notes that in the design and construct approach to construction the 'team approach' is almost mandatory. Construction managers and quantity surveyors like other professionals rely upon the skills and abilities of the other construction professionals to undertake their work. Over the past decade the RMIT University undergraduate degree in construction management has recognised this need for an integrated team-based approach and introduced a range of changes and course modifications to reflect this need. One such change has been the introduction of problem-based learning units in the first year of the undergraduate degree. The first year units emphasise the role of a team approach to construction.

One of the critical elements in a team approach is the appraisal of proposed ideas and solutions. Maister (1997) highlights the fact that effective teams do not develop overnight or by accident. He demonstrates that effective teams made up of groups of professionals in the construction industry can accomplish one or more goals at the same time. Developing this effectiveness is a difficult process. Gee et al. (1996) stress that effective teamwork recognises the limitations of the people that are working together. The ability to assess and evaluate the ideas and solutions proposed by others in the construction team is an important part of effective teamwork. This research paper examines one way of enabling future construction professionals to develop team skills and develop the ability to critically assess the solutions of their peers to a construction-based problem. It also provides the opportunity for students to measure their assessment skills against those of an industry expert panel including an architect, builder, construction manager and quantity surveyor.

\section{THE PROBLEM-BASED LEARNING UNIT}

The first year problem-based learning subjects constitute up to twenty-five per cent of the first year undergraduate degree in construction management at RMIT University. The final model-making unit combines theoretical concepts learnt in theory subjects and is normally undertaken in second semester. The unit is undertaken in the first year, as this year comprises study in all the technological subjects of the course. The aims of the unit are to:

- Combine theoretical concepts learnt in design, documentation and measurement classes;

- Allow students to experience working together in a design, management and construction team for a specified project;

- Encourage and further develop drawing techniques and three-dimensional presentation methods;

- Create a scale model of a construction project; and

- Experience group dynamics, teamwork, peer pressure and other relationships representative of the construction process. 
Students are grouped together and each group is given the title and other relevant information for a block of land. The students have to design a domestic timber-framed residence for the site. The dwelling must meet the client's brief and all the relevant building standards, codes and regulations including requirements for local government. Each group must produce a specified set of architectural and structural drawings of the house. Groups have to plan the construction sequence; the design, size and spacing of all timber members; work out quantities; and order the timber framing quantities from the department. Each group then constructs a scale model of the dwelling. The problem-based model approach is based upon a philosophy of learning and teaching that recognises student-centred approaches that directly link industry and professional needs with outcomes. In developing this model-making program at RMIT University, Outhred (1995) recognised the learners' pleas model cited by Mellander (1993). These 'pleas' include the ability of learners to use information and natural curiosity to 'discover' answers as well as the use of knowledge to draw conclusions. The philosophy behind the problem-based model making units also included the development of 'flexibility in approaches to teaching and learning (including assessment) that recognise and evaluate quality' (Outhred, 1995: 2). Over the past nine years these units have attempted to provide for students a critical, reflective orientation to learning. This orientation cannot be over-emphasised in the industry environment where competent construction professionals are required to manage a range of responsibilities and possess critical skills. McGeorge (1996) in commenting upon problembased learning approaches stresses the advantages of such an approach reflecting the real world demands of the construction industry.

Such an approach also emphasises the importance of learner empowerment. Brubacher (1977) and Chen et al. (1999) note this importance when they stress the value of students as creators of knowledge and skills, rather than reproducers of existing knowledge. In specifically commenting upon the building industry, Dall'Alba and Sandberg (1993: 2-5) note that the 'integrated learning approach prepares students to be independent learners and encourages the development of generalist problem-solving skills as well as technical competencies'.

The importance of teamwork in the work process is also a cornerstone of this problem-based model-making approach. In commenting upon teamwork in construction education at a tertiary level, McGettigan (1985:186) notes that:

The notion of team building requires some invested time to help the students appreciate the value of working to a common goal. Future development of a unit within the curricular very early in a course that develops an integrated approach to ethical matters and a teamwork ethos should be the foundation stone of any profession.

The creation of an integrated problem-based modelmaking unit within the first year construction management undergraduate degree at RMIT University has allowed students to experience the reality of a team approach to construction. However, the success of the unit has also created a number of problems associated with the group work. Emulating the construction industry approach where 'very disparate groups of professionals work together to achieve one or more goals' (Maister, 1997: 28-34) creates amongst the students a group approach to the learning outcomes where the measurement or assessment of the learning outcomes can be problematic. These 'problems' fall into a number of categories, which can be summarised as:

- Assessment of the group (team) outcome or final product;

- Assessment of the group (team) process; and

- Student-based issues in the group (team) approach.

The major 'problem' to arise from the success of the problem-based model-making unit is how to adequately assess the outcomes of the unit. Or more precisely what should be assessed? Having established the criteria for assessment, the second question to arise is: what method should be used to assess the criteria?

\section{ASSESSMENT OF THE PROBLEM-BASED MODEL} MAKING UNITS

Over the past nine years of the program, staff have used a very broad assessment model based upon a 'staff only' interpretation. The critical points for assessment were:

- Correctness of framing members;

- Clarity and accuracy of drawings;

- Presentation;

- Accuracy of measurements and materials;

- Method of model construction; and

- Demonstration of management skills, team and individual involvement and leadership (Outhred, 1995).

Although some effort was made to measure individual and team involvement, students were reliant upon the staff members' interpretation of their efforts. In reality, if a model met the measurable criteria, then all group members received the same mark irrespective of individual level of input. If a disagreement about team members efforts arose, there was no real objective model available to staff and a range of dispute mechanisms were employed by staff on a case-by-case basis. Often the group mark became the individual mark for all group members regardless of their individual input. This has led to concern amongst staff and learners alike. Habeshaw et al. (1989) stress that the type of assessment used can create problems for group members. They argue that where only the product or outcome is assessed, collaboration amongst group members can 
deteriorate and not all group members contribute evenly; some group members become 'free-riders'; others withhold resources and not all members contribute to the final product. Evidence from student feedback studies indicate that students want a system that gives them an opportunity to receive a grade that reflects their level of contribution to the work produced and to the group as a whole (Chin \& Overton, 2003).

There is little doubt that students want a fair and equitable system of assessment for group work. Students are concerned about assessment criteria that reward nonperforming group members. Bulman (1998) in her review of student-based concerns cited as the chief concern the possibility of grading or marking based upon the total group performance rather than individual efforts. Students are very concerned that the group work mark may not necessarily reflect their individual effort.

There is also some evidence that using group work for assessment encourages students to rely on their strengths to get them through, rather than tackling the areas they are unsure of or less competent in. Research by Habershaw et al. (1989) notes that assessing only the product of group work means learners only meet a limited part of the subject's learning objectives. Assessing the product of group work alone has significant consequences for learning as students tend to undertake only a limited part of the final product, normally the part with which they feel most comfortable.

Assessing the problem-based group work also raises the issue of which aspects of the work to assess. Should the assessment be based upon the group product or the group process in achieving the product or both? Astin et al. (1996) in addressing the principles of good assessment practice state that assessment requires not only attention to outcomes but also attention to the experiences that lead to these outcomes. That there may be merit in assessing the processes involved in creating the product is also supported by Chin and Overton (2003) who note that assessing the group work process creates interactive learning and transferable skills. Product only assessment of the group work models gives a limited insight into how the students developed throughout the project. In addition the quality of the final model may not be as high as the quality of the processes used by the students to create the model (and, of course, vice versa).

There is also the danger that ignoring the process involved creates less group interaction and collaboration than was intended by setting up the problem-based project. Nightingale et al. (1994) highlight in their research this unintended effect of assessing the product only - that is, this research showed that students worked individually then combined their contributions to achieve a better final mark.
Whether only the final product should be assessed is also the subject of some debate. In the construction industry it is the end product that is a symbol of achievement. Delivering a project that is inaccurately constructed, or fails to meet set standards or is even over budget, is not acceptable, even if the process involved in creating the project was above standard. The assessment of the final product only may be a more accurate replica of the world of work. Some researchers have noted the need for group work to mirror the real world, where essentially only outcomes are measured (Boud, 2001; Cohen et al., 1999). In addition, Chin and Overton (2003) note that 'one mark for all members' criteria very closely resembles the world of work where project team members all stand or fall by the project result.

Yet there is some debate about what skills are actually valued in 'the world of work.' If students are to use problembased model making units as an opportunity to acquire skills necessary in the construction industry then the assessment process needs to reflect the total range of skills - those involved in the model making process and also those involved in the final product. Bulman (1998) noted that one of the key objectives of group work is the idea that the group work mirrors the workplace where each individual has a responsibility to the group and thus this responsibility needs to be assessed. That the group process needs to be evaluated is best summed up by McGettigan (1985):

The construction industry requires a broad knowledge in many areas and with a growing technology base of knowing where to find out what is not readily known. Knowledge has become a primary value that is to be shared, invested and developed in a framework of common goals. It is important to emphasise the common value of working as a team; that each individual is recognised for their contribution or non-contribution to the team result ( $p$ 185).

If both the group process and the group product are to be assessed, what is the best model to produce a fair and accurate result?

\section{PEER ASSESSMENT: THE THEORETICAL FRAMEWORK}

Assessing group projects raises not only the issue of which aspects to assess. If both the process and product are to be assessed, who is best placed to assess each aspect? Given that much of the group work may be undertaken away from the lecturer's observation, it may be inappropriate for the assessment to lie solely in the hands of the lecturer. Linn (1991) and Williams (1996) conclude from their studies of group assessment that assessment by the teacher or lecturer alone restricts students taking responsibility for their own learning. Both authors conclude that there is considerable merit in peer-assessment strategies for project-based curricula. Peer assessment relies upon 
students evaluating the performance of others and providing assessments upon either or both the process used within the group and the final product produced. Nilson (2003) concludes that this form of assessment, commonly known as peer assessment can be very valuable.

But are students able to assess the work of their peers? Kerr et al. (1995) concluded that students are able to identify good work from bad, although there may be an upward bias in grading. He further concluded that students scoring abilities, as well as the quality of their work improved with practise at peer assessment. This is also endorsed by Brown, Race and Smith (1988) who found that students could undertake peer assessment but note the importance of educators setting the criteria in consultation with the students. The importance of students becoming experienced in peer assessment and assessment tasks is also important. If students have experience in peer assessment they are better able to establish and apply effective assessment criteria (Brown et al., 1988).

One of the important concerns with peer assessment is whether it is as reliable as lecturer/educator assessment. Topping (1999) found that peer assessment is as reliable as educator assessment. Also Pond (1997) found that peer review gave students increased ownership of the learning process and reduced incidence of collusive marking. More recently Slijismans et al. (2003) found that the involvement of students in assessment procedures had positive outcomes. That peer assessment can be effective in developing in the students critical thinking, communication and collaborative skills is also supported by a range of studies (Candy et al., 1994; Williams, 1992). It is clear that peer assessment with well published, well understood criteria which students have participated in establishing, can be a reliable method of assessment for groups.

There are some studies revealing problems with peer assessment. Candy (1994) notes that peer assessments may be biased and Pond et al. (1995) notes that students often grade more leniently than the instructor. A number of researchers have initiated models of peer assessment that allow input from both the lecturer and the students. Li (2001) introduced a model that allowed the educator to have input into the final grade to remove bias and over-marking. Rafig et al. (1996) used diaries to record the progress of a group, in addition to peer assessment and Goldfinch and Raeside (1990) devised a model of identifying 'which students did what' with the group, awarding a mark for the level of this work to the total project.

There is a need for a peer assessment model that encompasses the need for students to assess accurately and fairly yet adequately reflects the industry environment.

\section{THE PEER ASSESSMENT MODEL}

The peer assessment model adopted for the first year model-making unit was based upon objective criteria developed in consultation with industry experts and other lecturers. The criteria was developed along four main areas: Client proposal and architectural design; Energy efficiency design; Structural design; and Presentation.

Nilson (2003) notes that criteria that require a thorough examination of the work in question is likely to provide valuable peer feedback, rather than reliance on judgementbased personal reactions. Brown et al. (1997) also note the importance of students being clear about the assessment criteria. The assessment criteria for this model were carefully reviewed to eliminate personal opinions as much as possible and students were given the opportunity to discuss the criteria prior to the assessment period.

Within each of the assessment criteria a sub-set of questions and statements was developed so that students had objective measures to use in their assessments of the models.

The model is to be assigned an overall mark out of one hundred. Each of the four categories listed above is to be assigned a mark out of twenty-five and each of these marks summed.

\section{Client Proposal and Architectural Design (25 marks)}

Assess how well the model reflects the client's brief (10 marks) and the architectural design (15 marks).

\section{Client Brief (10 marks)}

Does the model reflect the client's brief?

The following points summarise the client's original brief for the design of the proposed residence:

- Maximise the view to the city;

- Provide an interesting and innovative design;

- Maximum total floor area of $110 \mathrm{~m}^{2}$;

- Single car garage;

- Two bedrooms;

- One bathroom;

- All wall construction is to be timber framed;

- Sub-floor is to be timber (except garage);

- The style of the house, roof and wall cladding must be approved by the council; and

- Frontage, rear and side setbacks are to be as per council and Rescode requirements.

Architectural Design (15 marks)

Check that the models are as per the architectural drawings. Examples of items to check include:

- Site set out;

- Location of internal walls; 
- Location and size of windows;

- Location and size of doors;

- Room heights;

- Room sizes; and

- Roof type.

\section{Energy Efficiency Design (25 marks)}

Assess how well passive solar design principles are used in the design. Items to assess could include:

- House orientation;

- Design to take advantage of solar access;

- Landscape design;

- Window location and size;

- Window protection;

- Correct insulation;

- Control of infiltration;

- Good ventilation;

- Zoned heating system; and

- Good use of thermal material.

Structural Design (25 marks)

- Are the stress grade, span, spacing and size of each timber member as per the structural drawings?

- Has the bracing been included as per the bracing design?

- Has each member e.g. bearer, joist, bottom plate, stud etc., been identified with the correct colour?

- Have all lintels to doors and windows been given the required numbers that correspond to the structural drawings? For example, the lintel for door D1 could have number LD1. which corresponds to the structural drawings; and

- Are the structural design drawings and workings provided? Do these drawings include references to the timber framing manual?

\section{Presentation (25 marks)}

Assess the presentation of the model. The following questions may be used as a guide for this assessment.

- Have the documents, including the architectural drawing and structural calculations been presented in a professional manner?

- Is the model well finished?

- Is the model complete?

- Is the model well presented?

THE LEARNING PROCESS

The assessment criteria were clearly explained and discussed with students, so that all students were well briefed about what was required throughout the modelmaking unit. Staff involved in the assessment process had undertaken a number of teaching and learning seminars reviewing assessment and were briefed about the process as well. At this first stage of assessment only the product, the model, was peer assessed. At a later stage peer assessment of the process, the group processes used will be undertaken. A total of sixty-five students in groups of six, were involved in the assessment. In selecting what elements to use to introduce the peer assessment model, the research by Kerr et al. (1995) indicating that differentials in grading may be overcome as students become more experienced at peer grading, was uppermost. As the students become familiar with peer assessment then they can further refine the model to assess the teamwork process.

Following the peer assessment an 'expert' panel representing a construction team will assess each model. The expert panel will consist of an architect, a quantity surveyor, an engineer and a builder. The role of the panel will be to provide a comparison between industry 'experts' and learners. The comparison will provide excellent feedback for the students on industry expectations and standards. The expert panel will use the same criteria as the peer assessment. Both the peer assessment and the expert panel will be conducted over the same time period.

\section{CONCLUSION}

Construction management and quantity surveying students need to develop professional skills that will enable them to work as part of a team. These 'team skills' are difficult to define yet important to develop. The ability to apply technical and professional skills in a team based modelmaking unit is applied in the first year of the RMIT University undergraduate degree in construction management. This year the ability to evaluate and assess the work of others was introduced into the unit as a way of giving students the opportunity to develop critical analysis and feedback skills in a construction setting. Students have the opportunity to apply technical criteria to the construction concepts created by their peers. The same students also have the opportunity to compare their evaluations and assessments with an industry expert panel. Students have the chance to measure their teamwork skills against their peers and receive expert feedback. Students have also had the opportunity to set the assessment criteria and discuss its validity in relation to the team environment.

At the time of writing the students are about to complete their first stage peer assessments. Already the feedback has been positive. Students have commented upon both the clarity and transparency of the assessment process. Students are also excited about the possibility of comparing their assessments of the models and the teamwork process with industry 'experts'. This has enhanced their learning experience and created a more professional approach to the work. An evaluation sheet detailing their responses to the new assessment model will be distributed once the expert panel has completed its comparison. The evaluation sheets will also allow for further research about the effectiveness of the peer assessment model and future direction for the construction management curriculum. 


\section{REFERENCES}

Astin, Banta, I., Cross, P., El-Khawas, E. and Ewell, P., (1996). Principles of Good Practice for Assessing Student Learning viewed 19 August 2003, http://ultibase.rmit.edu. au/articles/iune97/ameril.htm.

Beaumont-Kings, C. (1994). The Impact of Assessment on Learning. Paper presented at AARE Conference 1994 November, Newcastle, Australia.

Boud, (2001). Implementing Student Self-Assessment, viewed on 18 August 2003, http://www.iml.uts.edu.au/ Learnteach/assess/guides/O 112.htm.

Brown, Bull and Pendlebury, (1997). Assisting Students to Understand the Criteria for Group Assignments UTS, viewed 18 August 2003, http://www.imi.uts.edu.au/Learnteach/ assess/guides/0112.htm.

Brown, Race and Smith, (1988). Effective Laboratory Teaching. Effective Teaching in Higher Education, 5, 91-114.

Brubacher, J. (1977). On the Philosophy of Higher Education. Jossey Bass, San Francisco.

Bulman, T. (1998). Peer Assessment between Students in Colleges and Universities. Review of Educational Research 168 (3), 249-277.

Candy, P., Crebert, C. and O'Leary, J. (1994). Developing Lifelong Learners through Undergraduate Education. N.B.E.E.T. Australian Government Printing Service, Canberra.

Chalmers, D. (1996). Teaching for Learning at University: Theory and Practice. Kegan Paul, London.

Chen, S., Jefferies, M. and Conway, J. (1999). Ethics and Professional Values. In Themes and Variations in PBL (edited by Conway J.). APBLN, Newcastle, Australia.

Chin, P., and Overton, T. (2003). Assessing Group Work LTNS Physical Services, viewed 18 August 2003. http:// www.iml.uts.edu.au/Learnteach/assess/guides/Oll.htm.

Cohen and Simpson, (1999). Peer Learning and Assessment. Assessment and Evaluation in Higher Education, 24 (4), 413-426.

Conway, Kember, D., Sivan, A. and Wu, M.. (1993). Peer Assessment: an Individual's Contribution to a Group Project. Assessment and Evaluation in Higher Education, 18, 45-56.

Crooks, T.J. (1988). The Impact of Classroom Evaluation Practices on Students. Review of Educational Research, 58, 4.

Dall' Alba, G. and Sandberg, J. (1993). A Competency Based Approach to Education and Training. HERDSA News, $15(1), 2-5$.
Gatfield, (1999). Examining Student Satisfaction with Group Projects and Peer Assessment. Assessment and Evaluation in Higher Education 31, 365-377.

Gee, J. (1996). The New Work Order. Allen \& Unwin, New York.

Gibbs, G. (1992). Improving the Quality of Student Learning Bristol: Technical and Educational Services.

Gipps, C.V. (1994). Beyond Testing, Farmer Press, London.

Goldfinch and Raeside, (1990). Further Developments in Peer Assessment of Projects. Assessment and Evaluation in Higher Education. 1925-1934.

Habeshaw, (1989). Teaching Practicals. Preparing to Teach. (edited by Habeshaw) Routledge Paul, London.

Hodgeman, J. (1997). The Development of Peer and Selfassessment Strategies for a Design and Project-based Curriculum, viewed 18 August 2003. http:/ /ultibase.rmit. edu. au/Articles/dec97/hodgm1.htm.

Kember and Gow, (1991). A Challenge to the Stereotype Studies. Higher Education 16 (2), 117-128.

Kerr, P., Park, K. and Domazlicky, B. (1995). Peer Grading of Essays in a Principles of Microeconomics Course. Journal of Education for Business 70 (6), 357.

$\mathrm{Li}$, (2001). Some Refinements of Peer Assessment of Group Projects. Assessment and Evaluation in Higher Education 26, 5-18.

Lin, R., Liu, E. and Yuan, S. (1991). Complex Performance Based Assessment, Expectation and Validation Criteria. Educational Researcher 20, 15-21.

Linn, (1991).Complex performance Based Assessment Expectation and Validation Criteria. Educational Researcher $20,15-21$.

Maister, D. (1997). True Professionalism, Simon \& Schuster. New York.

McGeorge, D. (1996). An Advocacy for the Use of Problem Based Learning in Construction Management Education. AIB Papers 1, 4-9.

McGettigan, J. (1985). Building 1 BLX176 External Notes. Hawkesbury Agricultural College, Australia.

Mellander, K. (1993). The Power of Learning. American Society for Training and Development. New York.

Nightingale, (1994). Achieving Quality Learning in Higher Education. London Kogan Paul.

Niles, (1995). A Comparison of Overseas and Australian Students at an Australian University. International Journal of Intercultural Relations 19 (3), 369-385. 
Nilson, L. (2003). Improving Student Peer Feedback. College Teaching 51 (1) 34-39.

Outhred, G. (1995). Using Models to Develop Management Skills and Technical Understanding. Paper presented to AUBEA Conference, Sydney July 1995, Australia.

Pond, K., Ulhaq, R. and Wade, W. (1995). Peer Review: A precursor to peer assessment. Innovations in Education and Training International. 32, 314-323.

Pond, K. and UI-Haq, R. (1997). Learning to Assess Students Using Peer Review. Studies in Educational Evaluation. 23(4), 331-348.

Race, P. (2000). 500 Tips on Group Learning. Kogan Page Ltd. London.

Rafig, Y. and Fullerton, H. (1996). Peer Assessment of Group Projects in Engineering. Assessment and Evaluation in Higher Education 21, 35-40.

Ramburuth, (1997). Cross Cultural Learning Behaviour in Higher Education: Perceptions versus Practice. Paper presented at seventh LERN Conference on Learning, Melbourne, July 2000.

Sluijsmans, D., Brand-Gruwel, S. and Merrienboer, J. (2003). The Training of Peer Assessment Skills to Promote the Development of Reflection Skills in Teacher Education. Studies in Educational Evaluation 29 (1), 23.

Topping, (1999). Peer Assessment Between Students in College Universities. Review of Educational Research 68, 249-276.

Volet and Renshaw, (1996). A Short Term Longitudinal Investigation of Cross Cultural Differences in Study Approaches. British Journal of Educational Psychology. 64, 301-318.

Williams, L. (1996). Large Classes, Computers and Assessment. Tertiary Education News, University of Queensland. 6 (1), 4.

Winter, (1995). Development of Criteria for Team Work viewed 18 August 2003, http:/ /www.iml.uts.edu.au/ Learnteach/assess/guides/0112.htm. 


\title{
INSTRUCTIONS AND GUIDELINES FOR AUTHORS TO THE AUSTRALIAN JOURNAL OF CONSTRUCTION ECONOMICS AND BUILDING
}

SUBMISSION

Two issues (June and December) per annual volume of the journal are planned. Authors are requested to submit papers for publication at any time to:

\author{
Ms Lynn Adams \\ Australian Institute of Quantity Surveyors \\ PO Box 301 \\ Deakin West ACT 2600 \\ AUSTRALIA \\ T] +6126282 2222 \\ F] +61 262852427 \\ E] lynn@aiqs.com.au
}

Papers will be referred to acknowledged experts for comment as to suitability, originality, interest and content. Only those receiving favourable recommendations from the referees will be accepted for publication. If an author is uncertain about whether a paper is suitable for publication, it is acceptable to submit a synopsis first.

\section{Submission of disks}

Disks must be supplied with the manuscript. Contributors should submit a 3.5 disk formatted on a PC or Macintosh computer in MS Word (version 5 and above) and/or Excel (version 4 and above) or email their papers to the above address.

\section{Effective communication}

The paper should be written and arranged in a style that is succinct and easily followed. An informative title, a concise abstract and a well-written introduction will help to achieve this. Simple language, short sentences and a good use of headings all help to communicate information more effectively. Discursive treatments of the subject matter are discouraged. Figures should be used to aid the clarity of the paper, not pad it out. Think about your reader.

\section{English language assistance}

As the language of the publication is English, it is strongly recommended that non-English speaking authors seek assistance from a competent English writer to ensure the spelling, grammar and style are correct. The Editor may be able to assist in identifying appropriate people to consult.

\section{Manuscript}

\section{(a) Presentation}

Depending on their nature, papers may be up to 5,000 words in length. Manuscripts should be typed 1.5 spacing, left hand justified, including references. A brief autobiographical note should be supplied including full name, position held and name of employing organisation. The manuscript should be arranged under headings and subheadings.

\section{(b) Title page}

The first page of the manuscript must contain the full title, the affiliation and address of the author(s), a running title of not more than 75 characters and spaces, the name and address of the author who will be responsible for correspondence and correcting the proofs, and up to five keywords for the purposes of indexing.

\section{(c) Keywords}

Authors should also provide 5 keywords or descriptors that clearly describe the subject matter of the article. These terms have two purposes: to help describe the subject content of an article to prospective readers; to index the article for retrieva from a database or bibliography. Such keywords might include: Country, geographical area, e.g. New Zealand, Micronesia; Organisation/ organisation related, e.g. Building Industry, Public Works; People, e.g. consultants, quantity surveyors, subcontractors; Specific processes, technologies or applications, e.g. databases, TQM, advanced manufacturing technology; Broad functions or disciplines, e.g. information technology, cost management, innovation studies; Other processes and subject areas, e.g. industrial relations, economics, design, research 


\section{(d) The abstract}

An abstract should be included. It must not exceed 200 words and must precis the paper giving a clear indication of the conclusions it contains.

\section{(e) Illustrations}

Illustrations must accompany the manuscript but should not be included in the text. Photographs, standard forms and charts should be referred to as 'Fig. 1', 'Fig. 2' etc. They should be numbered in the order in which they are referred to in the text. Indicate where in the text you wish the figure to appear. Send accurate and clear drawings to enable good reproduction.

Tables should be numbered consecutively and independently of any figures. Each table must have a number, a brief title, and headings down and across. Type tables on separate sheets of paper, and indicate in the text where you wish them to appear.

Photographs, preferably transparencies, should be labelled with the figure number and an indication of which is top. Where lettering is to appear on the photograph, two prints should be supplied, one of which should be left unlettered.

\section{(f) Measurements}

Metric units should be used; if other units are used then metric equivalents should be given in parentheses.

\section{(g) References}

The Harvard system is used. References in the text should be quoted in the following manner: Smith (1975) ... or ... Brown and Green, (1976) ... or, if there are more than two authors ... Jones et al.. (1980). References should be collected at the end of the paper in alphabetical order by the first author's surname. If references to the same author have the same year, they should be differentiated by using 1980a and $1980 \mathrm{~b}$ etc. The style should follow the examples below:

Smithers, N. (1966). Cost benefit analysis in town planning. Urban Studies, 33, 4-27.

Stone, P. A. (1980). Building Design Evaluation: Costs-InUse. E. \& F.N. Spon, London.

Burnes, S. (1981). Implementation of public policy. In Policy and Action (edited by S. Barrett and C. Fudge), 1-33. Chapman and Hall, London.

If no person is named as the author the name of the organisation should be used, for example:

Australian Institute of Quantity Surveyors. (1980). Report on Quantity Surveying Methods, Canberra.

To reference a website, include the author (be it an individual, organisation or institution), title of document, date the document was created, date it was viewed and the URL, for example:
International Council for Research and Innovation in Building and Construction 2000, W100-Environmental Assessment of Buildings, Results, International Conference Sustainable Building 2000, 22-25 October, Maastricht, The Netherlands viewed 14 July 2003, <http://www.cibworld.nl/pages/ ib/0005/Pages/Around/W100.html>.

(h) Notes

A limited number of explanatory endnotes is permissible. These should be numbered 1,2, 3, consecutively in the text and denoted by superscripts. They should be typed on a separate sheet of paper at the end of the text. Endnotes should not be used for academic or project citations.

\section{Proofs}

Proofs will be sent to the corresponding author for correction. The difficulty and expense involved in making amendments at proof stage make it essential for authors to prepare their manuscript carefully: any alterations to the original text are strongly discouraged. Our aim is rapid publication: this will be helped if authors provide good copy following the above instructions, and return their proofs as quickly as possible. The editors reserve the right to amend style, grammar and typographical errors without reference to the authors.

\section{Copyright}

Submission of an article to the Australian Journal of Construction Economics and Building is taken to imply that it represents original, unpublished work, not under consideration for publication elsewhere. Authors submitting articles for publication warrant that the work is not an infringement of any existing copyright and will indemnify the publisher against any breach of such warranty.

On submitting a manuscript, authors will be asked to transfer the copyright for their article to the Publisher if and when the article is accepted for publication. The copyright covers the exclusive rights to reproduce and distribute the article, including reprints, photographic reproductions, microfilm or any reproduction of a similar nature, and translations.

Permission to publish illustrations must be obtained by the author before submission and any acknowledgments should be included in the figure captions.

\section{Refereeing procedure}

The decision whether or not to publish an article is the Editor's. At least two members of the Editorial Board, and/or other acknowledged experts will be consulted. 
Scanner's note: This is a blank page 
